\title{
Course of recovery and prediction of outcome in young patients in a prolonged vegetative or minimally conscious state after severe brain injury: An exploratory study
}

Citation for published version (APA):

Eilander, H. J., van Heugten, C. M., Wijnen, V. J. M., Croon, M. A., de Kort, P. L. M., Bosch, D. A., \& Prevo, A. J. H. (2013). Course of recovery and prediction of outcome in young patients in a prolonged vegetative or minimally conscious state after severe brain injury: An exploratory study. Journal of Pediatric Rehabilitation Medicine, 6(2), 73-83. https://doi.org/10.3233/prm-130241

Document status and date:

Published: 01/01/2013

DOI:

10.3233/prm-130241

Document Version:

Publisher's PDF, also known as Version of record

\section{Document license:}

Taverne

\section{Please check the document version of this publication:}

- A submitted manuscript is the version of the article upon submission and before peer-review. There can be important differences between the submitted version and the official published version of record. People interested in the research are advised to contact the author for the final version of the publication, or visit the DOI to the publisher's website.

- The final author version and the galley proof are versions of the publication after peer review.

- The final published version features the final layout of the paper including the volume, issue and page numbers.

Link to publication

\footnotetext{
General rights rights.

- You may freely distribute the URL identifying the publication in the public portal. please follow below link for the End User Agreement:

www.umlib.nl/taverne-license

Take down policy

If you believe that this document breaches copyright please contact us at:

repository@maastrichtuniversity.nl

providing details and we will investigate your claim.
}

Copyright and moral rights for the publications made accessible in the public portal are retained by the authors and/or other copyright owners and it is a condition of accessing publications that users recognise and abide by the legal requirements associated with these

- Users may download and print one copy of any publication from the public portal for the purpose of private study or research.

- You may not further distribute the material or use it for any profit-making activity or commercial gain

If the publication is distributed under the terms of Article $25 \mathrm{fa}$ of the Dutch Copyright Act, indicated by the "Taverne" license above, 


\title{
Course of recovery and prediction of outcome in young patients in a prolonged vegetative or minimally conscious state after severe brain injury: An exploratory study
}

\author{
Henk J. Eilander ${ }^{\mathrm{a}, *}$, Caroline M. van Heugten ${ }^{\mathrm{b}, \mathrm{g}}$, Viona J.M. Wijnen ${ }^{\mathrm{a}}$, Marcel A. Croon ${ }^{\mathrm{c}}$, \\ Paul L.M. de Kort ${ }^{\mathrm{d}}$, D. Andries Bosch ${ }^{\mathrm{e}}$ and Arie J.H. Prevo ${ }^{\mathrm{f}}$ \\ ${ }^{a}$ Project VLB-NAH, Tilburg, Division Research, Rehabilitation Centre Leijpark, The Netherlands \\ ${ }^{\mathrm{b}}$ School for Mental Health and Neuroscience, Faculty of Health, Medicine and Life Sciences, Maastricht \\ University, Maastricht, The Netherlands \\ 'Statistics and Methodology Department, Faculty of Social Sciences, Tilburg University, Tilburg, The Netherlands \\ ${ }^{\mathrm{d}}$ St.Elisabeth Hospital, Division of Neurology, Tilburg, The Netherlands \\ e Department of Neurosurgery, Academic Medical Centre, Amsterdam, The Netherlands \\ ${ }^{\mathrm{f}}$ Rehabilitation Centre de Hoogstraat, Utrecht, The Netherlands \\ ${ }^{g}$ Department of Neuropsychology and Psychopharmacology, Faculty of Psychology and Neuroscience, Maastricht \\ University, Maastricht, The Netherlands
}

Accepted 17 March 2013

\begin{abstract}
.
AIMS: To explore the course of recovery of consciousness and factors predicting the outcome of severe brain injury with a prolonged period of unconsciousness in children and young adults receiving a specialized rehabilitation treatment, the Early Intensive Neurorehabilitation Programme (EINP).

METHODS: A cohort of forty-four patients aged 1.6-25.5 years $(M=16.0)$ with traumatic acquired brain injury (TBI) or nontraumatic acquired brain injury (nTBI) were examined using the Western Neuro Sensory Stimulation Profile every two weeks, from the application for EINP until discharge. The level of consciousness was assessed with the Post-Acute Level of Consciousness Scale, and the level of disability was determined by the Disability Rating Scale. Long-term level of disability of all TBI patients $(N=32)$ was assessed between 2.0 and 4.4 years after discharge from EINP.

RESULTS: Two-thirds of all patients recovered to consciousness. Three recovery patterns were identified: remaining in a vegetative state (VS), slow recovery of consciousness, and fast recovery of consciousness. In the long-term, 11 of the TBI patients were severely disabled, 13 were moderately disabled, and 4 were mildly disabled. All TBI patients who were in VS at discharge either had deceased, or recovered to a very severely disabled state.
\end{abstract}

CONCLUSIONS: Three recovery patterns identified in an early stage after starting EINP made it possible to predict long-term level of disability.

Keywords: Brain injury, level of consciousness, long-term outcome, paediatric rehabilitation, minimally conscious state, vegetative state

\section{Introduction}

*Corresponding author: H.J. Eilander, Bankven 17, 5052 BA Goirle, The Netherlands. Tel.: +31 625153 255; E-mail: h.j. eilander@brain-consult.nl.
Recovery of consciousness of young patients who remain unconscious for at least one month after se- 
vere brain injury is uncertain [1]. In 1994, the MultiSociety Task Force (MSTF) on the persistent vegetative state used earlier outcome research and calculated recovery percentages at 12 months after injury of between $13 \%$ (in children with non-traumatic brain injury, nTBI) and $62 \%$ (in children with traumatic brain injury, TBI) [2,3]. As no comparable studies have been published since then, these percentages are still the accepted standards [4]. In the meantime, thinking about the vegetative state (VS) has changed dramatically, with two studies describing different levels of consciousness, especially in the post-acute phase. The International Working Party on the Management of the Vegetative State in 1996 introduced the concept of the "low awareness state" (LAS) [5], whereas the 1997 Aspen Workgroup on the Vegetative and Minimally Conscious States introduced the "minimally conscious state" (MCS) [6], Distinguishing between these different levels of consciousness is one of the key issues in assessing recovery and predicting outcome. Although these studies resulted in consensus among rehabilitation specialists in the United States about the definition and diagnostic criteria of the MCS [7], there are no unique and globally accepted definitions of VS and MCS [4,8].

In addition, it is still unclear as to whether any treatment in the post-acute phase can contribute to the recovery of consciousness [9]. In a review on the rehabilitation of patients in VS and MCS, Elliott and Walker [10] presented some arguments regarding early therapeutic interventions. The human brain is now known to show greater plasticity than ever thought, and studies have found that a larger number of patients recovered than expected [11]. Early interventions have been associated with better outcomes in severely braininjured patients, and intensive specialist rehabilitation programs have been shown to be both effective and cost-effective in the long-term [12]. Andrews stated that the rehabilitation of persons with profound brain damage requires the skills of a truly interdisciplinary team [13], which must be appropriately trained [14]. The ultimate evidence for the effectiveness of rehabilitation versus no treatment, however, is lacking [10].

An important question is whether it is possible to predict at an early stage what level of recovery can be achieved in vegetative or minimally conscious patients, in order to facilitate appropriate and timely referral to a specialist rehabilitation unit [15]. Aspects to be studied as possible predictors include injury characteristics [16], the initial Glasgow Coma Scale score [15,17], the time spent in the intensive care unit (ICU) [18], and the level of consciousness at different moments.
In the Netherlands, an Early Intensive Neurorehabilitation Programme (EINP) for children and young adults in a prolonged vegetative or minimally conscious state after severe brain injury has been provided since 1987 . EINP is a multidisciplinary and multifaceted program, aiming at the recovery of all faculties of human functioning, but first of all at the recovery of consciousness. A brief description of EINP is presented in Appendix 1.

In an earlier study, we investigated retrospectively, based on medical files, the outcome of 145 patients who received EINP [19]. The study found that almost two-thirds of the patients had attained full consciousness at discharge. The outcome at discharge correlated with the level of consciousness at admission, the etiology, and the interval since injury. The present study is a prospective longitudinal observational study to explore the development of the level of consciousness in a cohort of patients receiving EINP, giving rise to the following research questions:

- What is the course of recovery of consciousness during EINP in the total group (TBI plus nTBI)?

- Can recovery of consciousness in the total group (TBI plus nTBI) be predicted by any of the variables studied?

- What is the long-term level of disability of the TBI patients?

- Can the level of long-term disability of the TBI patients be predicted?

As far as we know, this is the first study to longitudinally follow a cohort of unconscious young patients who received a rehabilitation program aiming at the recovery of consciousness.

\section{Methods}

\subsection{Patients}

The participants in this study were all patients $(n=$ 44) admitted to EINP between January 2001 and September 2003. Criteria for admission to EINP were: acquired brain injury, age 0-25 years at the time of application for EINP, within 6 months of injury, and having a Post-Acute Level Of Consciousness scale (PALOC-s) [20] score $(\mathrm{Pa}) \leqslant 6$ at admission.

In view of the heterogeneity of the small group of 12 nTBI patients and to ensure comparability with other studies, the long-term outcome study was restricted to the TBI patients $(N=32)$. As a consequence, some 
analyses are related to 44 patients and some to 32 patients.

One patient was receiving neurostimulants at the time of the last 4 of the 6 measurements. Most patients were receiving various other medications (antiepileptics, anti-depressants, sedatives, hypnotics, etc), which may influence brain functioning. In view of the individual differences it was not possible to control for the effects of these influences.

\subsection{Procedures}

The study had a one-group repeated measures design. Patients were examined in the hospital by the first author within one week after EINP was applied for, and then again every two weeks until admission to EINP. In some instances, the time between application for and admission to EINP was too short to allow the patients to be visited at the hospital. The examination was repeated two or three days after admission to EINP, and then repeated every two weeks until discharge from EINP. The examination during EINP took place in a quiet room with a constant temperature $\left(23 \pm 1^{\circ} \mathrm{C}\right)$, always at the same time of day (3:00 $\mathrm{pm})$, immediately following the afternoon resting period. Depending on their condition, patients were examined either sitting in an upright position in bed or sitting in a wheelchair. The examination followed the protocol of the Western Neuro Sensory Stimulation Profile (WNSSP [21]). This protocol was developed to examine severely impaired brain-injured patients with diminished consciousness, and can be used for clinical evaluation as well as for the study of recovery patterns. The WNSSP consists of 33 items, examining a broad range of behaviours: arousal and attention, expressive communication, and responses to auditory, visual, tactile and olfactory stimulation. At the end of each examination, the level of consciousness (LoC) and the level of disability (LoD) were established by scoring the outcome scales.

We also recorded demographic data, the initial Glasgow Coma Scale score [17] at admission to the hospital (iGCS), and the length of stay at the ICU.

The long-term level of functioning of all TBI patients was established by interviewing one of the nearest family members (usually a parent) by telephone, administering the Disability Rating Scale (DRS). This interview was performed by a physiatrist who had no information about the patients apart from their name, gender and age.

\subsection{Measures}

\subsubsection{Post-acute level of consciousness scale (PALOC-s)}

Assessment of the level of consciousness was conducted by using the Post-Acute Level of Consciousness scale (PALOC-s), which was developed and evaluated in the research project of which this study is a part [20]. PALOC-s has been found to be reliable and valid. It involves eight hierarchal states: Coma (P1), VS hypo-reactive (P2), VS reflexive (P3), VS highly active or reactive (P4), MCS transitional state (P5), MCS inappropriate (P6), MCS appropriate (P7), and Consciousness (P8), giving rise to scores ranging from 1 to 8 . Each level is characterised by three to four short descriptive sentences [20].

\subsubsection{Disability Rating Scale (DRS)}

The Disability Rating Scale (DRS) was used as a measure to establish the global level of disability during EINP as well as in the long-term. The DRS has been developed for quantitative assessment of the disability level of patients with severe brain injury [22]. The DRS consists of eight items, which are summed to provide an overall score from 0 (no disability) to 29 (extremely vegetative). A score of 30 is given when a patient has died. The DRS has been recommended as one of the most appropriate instruments to assess the long-term outcome of severely brain-injured patients [22-24].

In this paper, we differentiate between the DRS scores collected together with the PALOC-s during EINP and the DRS scores collected from the TBI patients in the long-term by referring to the latter as "DRS long-term".

\subsection{Analyses}

To enable the DRS long-term scores to be compared with results of earlier studies, the raw DRS scores were collated into eight category scores [23]. This option of categorisation was already proposed in the original publication presenting the DRS, by Rappaport et al. [22], and was found to be almost as reliable as using the raw scores [25].

Frequency tables were used to describe the population and the outcome scores. Distribution plots were used to present scores graphically. Correlation coefficients were calculated by means of the Spearman-r correlation coefficient, due to the limited number of patients. Age differences, as well as the differences 
in 'Time between injury and admission to EINP' and the 'Length of stay in EINP' between the TBI group and the nTBI group, were tested by means of a t-test. The mean levels of consciousness at admission for the three outcome groups were compared by means of the Kruskal-Wallis test, followed by a pairwise posthoc test with Bonferroni correction to determine the nature of the differences.

Separate multilevel regression analyses were carried out for the PALOC-s and DRS, using gender, age, cause of injury, treatment, and time since discharge from the ICU as explanatory variables. Cause of injury was defined as "TBI" versus "nTBI", and treatment was defined as "not yet admitted to EINP", which included the first assessment at two or three days after admission to EINP, versus "participating in EINP", thus differentiating between patients' scores before and during the rehabilitation program. The regression coefficients of gender, age, cause, and treatment were treated as fixed effects. The coefficient of time and the constant regression coefficient were treated as random effects. A random constant regression coefficient allows the consecutive measurements of the dependent variable for the same individual to be correlated. The random regression coefficient of time allows the development of the dependent variable over time to be subject-specific.

Data were analysed with the Statistical Package for the Social Sciences (IBM SPSS 2010). Alpha was set at 0.05 .

\section{Results}

\subsection{Patients characteristics}

The main characteristics of all patients consecutively admitted to EINP in the study period are presented in Table 1. Most patients had suffered traumatic brain injury ( $n=32 ; 73 \%$ ). The mean initial GCS at hospital admission was 4.8. The initial GCS of 5 nTBI patients was unknown or not scored.

The mean age of the patients at the time of injury was 16.0 years $($ median $=18.1$ years, range $1.6-25.5$ ). There was a significant difference in age between the TBI patients (mean age $=18.4$ years) and the nTBI patients (mean age $=9.4$ years) $(t$-test $=3.99 ; p<0.01)$. Twenty-eight of the patients $(63.6 \%)$ were male. All but two of the patients were admitted to EINP within 6 months after injury (median $=2.1$ months; range $=$ 0.8-6.6). Two patients exceeded the criterion of being

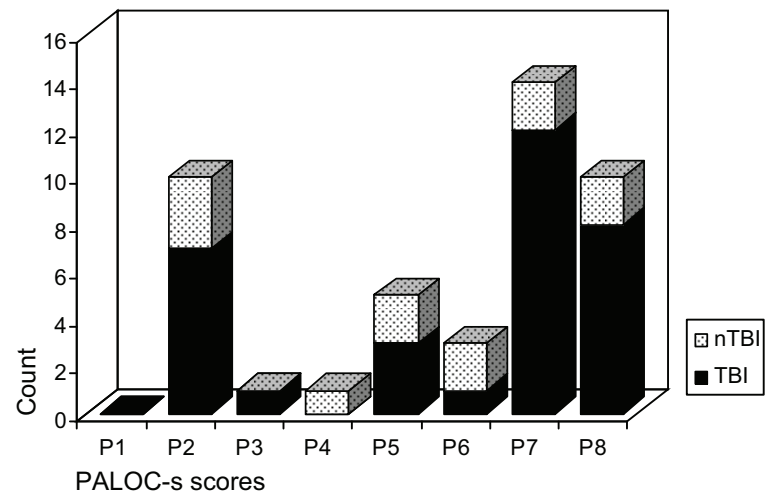

Fig. 1. Distribution of the PALOC-s scores of the two subgroups (TBI and nTBI) at discharge from EINP.

admitted within 6 months, by 20 and 9 days, respectively, because of a long waiting list (111 and 68 days, respectively). There was no significant difference in number of days between injury and admission to EINP between the TBI patients and the nTBI patients.

Patients were discharged from EINP when they had regained consciousness according to the rehabilitation team, or when no further recovery of the level of consciousness was observed over a 4-6 week period. The TBI group stayed significantly more days in EINP compared to the nTBI-group $(t=2.50 ; p=0.02$ )

\subsection{Level of consciousness}

As can be seen in Fig. 1, the distribution of PALOCs scores at discharge was U-shaped. Most of the patients $(54.5 \%)$ recovered to PALOC-s level 7 (consistent minimally conscious level) or 8 (conscious). Almost a quarter $(22.7 \%)$ of the patients remained extremely vegetative (PALOC-s level 2), and an equal proportion $(22.7 \%)$ was distributed over the PALOC-s categories P3 to P6. The U-shaped pattern was found only for the group of TBI patients. The outcome in the nTBI group was more or less equally distributed over the PALOC-s categories.

All TBI patients with a score of P4 (VS highly reactive) or higher on the PALOC-s at admission recovered to PALOC-s level P7 or P8 (MCS appropriate or conscious). In the nTBI group, the only patient who scored P4 on the PALOC-s at admission did not attain PALOC-s level P7 or P8, because of an evolving unstable neurological condition due to a brain tumour. Of the 22 TBI patients who had a PALOC-s score of P3 or less at admission, 10 recovered to PALOC-s level P7 or P8. Of the eight nTBI patients with a PALOC-s score 
Table 1

Demographic characteristics

\begin{tabular}{|c|c|c|c|}
\hline & TBI $(n=32)$ & & nTBI $(n=12)$ \\
\hline \multicolumn{4}{|l|}{ Cause } \\
\hline Traffic & $30(94 \%)$ & Cardiac arrest & $2(17)$ \\
\hline \multirow[t]{3}{*}{ Other } & $2(6)$ & Near-drowning & $3(25)$ \\
\hline & & Stroke & $3(25)$ \\
\hline & & Other & $4(33)$ \\
\hline \multicolumn{4}{|l|}{ Age at admission to EINP } \\
\hline $0-5$ years & $2(6)$ & & $5(42)$ \\
\hline $6-10$ & $2(6)$ & & $2(17)$ \\
\hline $11-15$ & $2(6)$ & & $3(25)$ \\
\hline $16-20$ & $13(41)$ & & $1(8)$ \\
\hline $21-25$ & $13(41)$ & & $1(8)$ \\
\hline Mean age $(\mathrm{SD}) * *$ & 18.4 years $(6.1)$ & & 9.4 years $(6.9)$ \\
\hline \multicolumn{4}{|l|}{ Gender } \\
\hline Male/Female & $21 / 11(66 / 34)$ & & $7 / 5(58 / 42)$ \\
\hline \multicolumn{4}{|l|}{$\mathrm{GCS}^{1}$ at hospital admission } \\
\hline Mean (SD) & $4.5(1.3)$ & & $4.3(1.3)$ \\
\hline Unknown & 0 & & $8(67)$ \\
\hline \multicolumn{4}{|l|}{ Length of stay at $\mathrm{ICU}^{2}$ in days } \\
\hline Mean (SD) & $33(26.7)$ & & $20(18.0)$ \\
\hline Unknown & 0 & & 1 \\
\hline \multicolumn{4}{|l|}{ LoC $^{3}$ at admission to EINP } \\
\hline Vegetative state & $24(75)$ & & $9(75)$ \\
\hline Minimally conscious state & $8(25)$ & & $3(25)$ \\
\hline \multicolumn{4}{|c|}{ Time between injury and admission to EINP in days } \\
\hline Mean (SD) & $72(39)$ & & $68(23)$ \\
\hline \multicolumn{4}{|l|}{ Length of stay at EINP in days } \\
\hline Mean (SD)* & $109(39)$ & & $81(30)$ \\
\hline
\end{tabular}

${ }^{*} p<0.05,{ }^{*} p<0.01 .{ }^{1} \mathrm{GCS}=$ initial Glasgow Coma Scale score at time of injury. ${ }^{2} \mathrm{ICU}=$ Intensive Care Unit. ${ }^{3}$ LoC $=$ Level of consciousness.

of P3 or less at admission, only one attained PALOC-s level P7.

Related to the initial PALOC-s score at admission, there were no significant differences in LoD (DRS) at discharge between the TBI patients and the nTBI patients $(Z=-1.13, p=0.26)$.

\subsection{Course of recovery}

The course of recovery was determined by examining recovery rates. Figure 2 shows three different courses of recovery. First, we identified all patients who remained in a vegetative state (Remaining vegetative). This was the case for 12 of the 44 patients. Secondly, we identified all patients who were discharged before the $12^{\text {th }}$ week after admission (Fast recovery of consciousness), which is the time in EINP when the regular progress evaluation is scheduled. This was the case for 11 of the 44 patients. All but one of these patients recovered relatively quickly to consciousness or to a consistent minimally conscious level, and were discharged to a regular rehabilitation program. Finally, all other patients (Slow recovery of consciousness, 21 of the 44) generally showed a slow recovery rate, and some of them remained in a minimally conscious state (PALOC-s level P5 or P6) not sufficient for further rehabilitation. The lowest PALOC-s score in this group rose quickly between measurement 8 ( 8 weeks after admission) and measurement 10 (12 weeks after admission). The number of patients with low PALOC-s scores in this "Slow recovery of consciousness" group decreased rapidly during the first 6 weeks of admission to EINP: 7 of the 20 patients were scored as level P2 at admission, compared to 3 of the 21 patients at 6 weeks after admission.

Figure 2 further shows that the three groups generally differed in mean PALOC-s scores at admission: the "Remaining vegetative" group had a mean PALOC-s score of 2.2 (range 1-3), the "Slow recovery of consciousness" group had a mean PALOC-s score of 3.2 (range 2-6) and the "Fast recovery of consciousness" group had a mean PALOC-s score of 4.2 (range 2-6). These differences between the three groups were significant (Kruskal-Wallis test $\chi^{2}=9.86 ; d f=2$; $p<0.01$ ). A pairwise posthoc analysis with Bonferroni correction revealed that the "Remaining vegeta- 

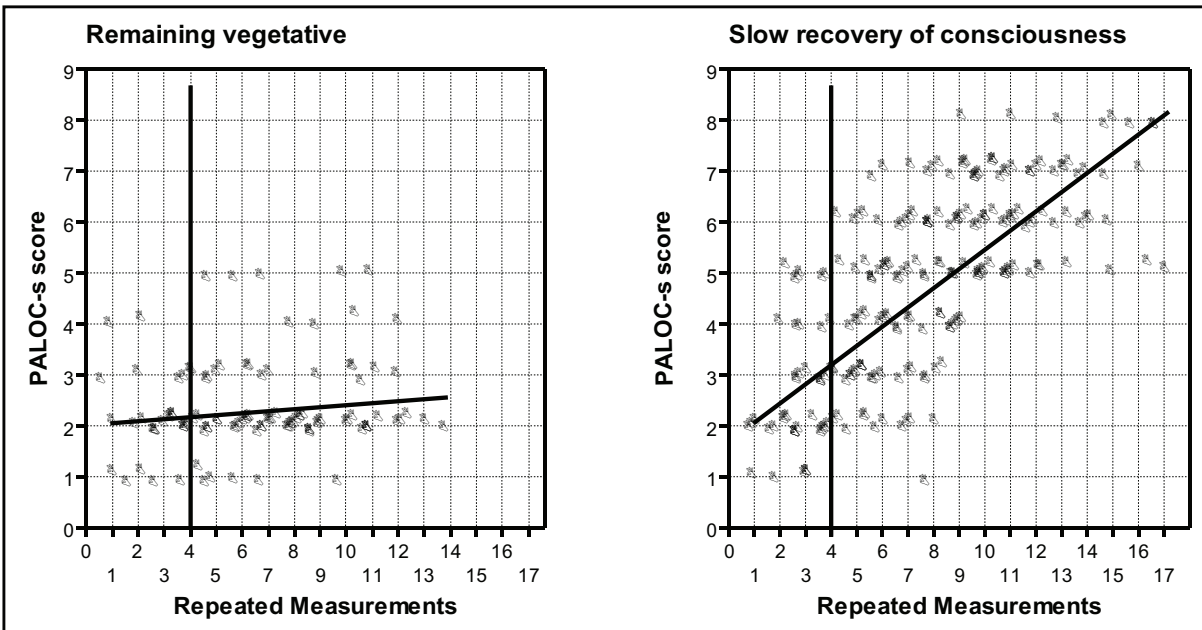

Fast recovery of consciousness

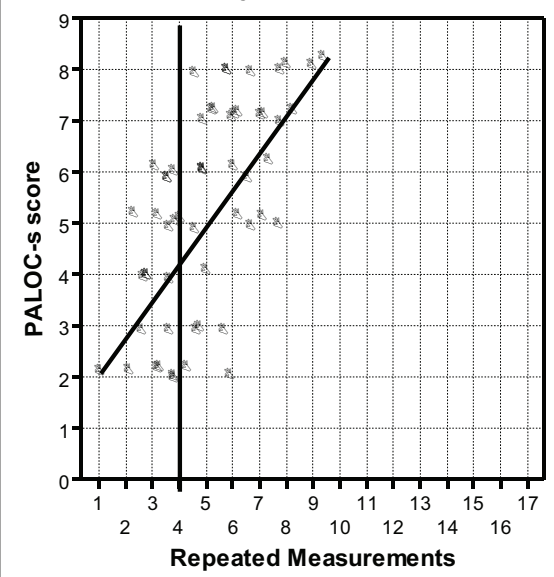

Remaining vegetative: $\mathrm{N}=12$ patients

Slow recovery of consciousness: $\mathrm{N}=21$ patients

Fast recovery of consciousness: $\mathrm{N}=11$ patients

Measurements 1-3 were done at the hospital, before admission. Not all patients participated. Measurement 4 is the first one after admission to EINP, on the second or third day. One patient could not be measured for the first time until two weeks after admission.

The number of patients per measurement decreased gradually, depending on the patients' discharge date.

Fig. 2. Distribution of the levels of consciousness assessed using PALOC-s in all repeated measurements over time, and the corresponding linear regressions, in three different outcome groups. Each triangle represents one measurement of one patient.

tive" group performed significantly worse at admission than the "Fast recovery of consciousness" group $(p=$ 0.018 ) and also, but not significant, compared to the "Slow recovery of consciousness" group ( $p=0.057)$. The difference in LoC at admission between the two groups of patients who eventually regained consciousness (i.e. "slow recovery of consciousness" and "fast recovery of consciousness" groups) was not significant $(p=0.345)$.

\subsection{Prediction of the recovery course during EINP}

The results of the multilevel regression analysis showed positive associations between "Time since discharge from ICU" and the PALOC-s scores (BE 0.03; $p<0.01$ ), as well as the DRS scores (BE $-0.07 ; p<$ 0.01 ), indicating that the percentage of patients recov- ering consciousness increases over time. None of the other variables we included (gender, age, cause and treatment) had any significant predictive effect $(p>$ 0.05) (see Table 2).

Further visual analysis showed large inter-individual differences with respect to the time course of the PALOC-s and the DRS, implying that although the association we found may apply to the cohort, it is impossible to predict the outcome for each individual patient based on the time course.

\subsection{Long-term level of disability}

The long-term outcome of the TBI-patients was determined between 2.0 and 4.4 years after discharge (mean $=3.1$ years).

The results show a peak of 13 patients for level 6 of the DRS long-term, which can be defined as mod- 
Table 2

Estimates of fixed effects from the multilevel analysis for PALOC-s and the DRS $(N=44)$

\begin{tabular}{lccccccc}
\hline & \multicolumn{3}{c}{ PALOC-s } & & \multicolumn{3}{c}{$\mathrm{DRS}$} \\
\cline { 2 - 4 } \cline { 6 - 7 } & $\mathrm{BE}$ & $\mathrm{Se}$ & $\mathrm{T}$ & & $\mathrm{BE}$ & $\mathrm{Se}$ & $\mathrm{T}$ \\
\hline Gender & 0.09 & 0.47 & 0.20 & & -0.21 & 0.94 & -0.22 \\
Age & 0.06 & 0.04 & 1.68 & & -0.10 & 0.07 & -1.39 \\
Cause & 0.57 & 0.60 & 0.95 & & -0.55 & 1.19 & -0.46 \\
Treatment & 0.28 & 0.14 & 1.60 & & -0.42 & 0.35 & -1.22 \\
Time & 0.03 & 0.00 & $7.07^{*}$ & & -0.07 & 0.01 & $-6.32^{*}$ \\
\hline
\end{tabular}

$* p<0.01$

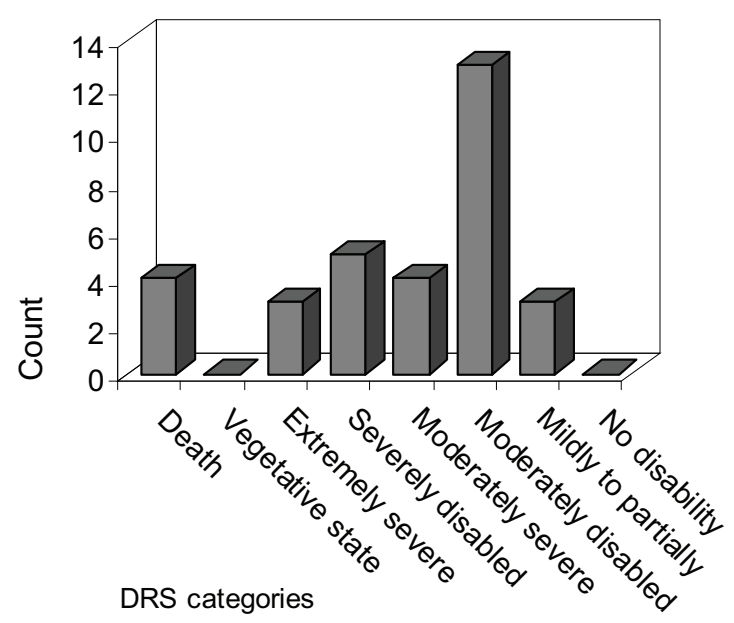

Fig. 3. Frequencies of the DRS long-term category scores of the TBI group $(N=32)$

erately disabled [22]. The other 19 patients were more or less equally distributed over five of the other categories (see Fig. 3). None of the patients were in the categories "vegetative" and "no disability". Of the seven patients who were in VS at discharge, four had since died. The remaining three patients were categorized as very severely disabled.

\subsection{Prediction of long-term level of disability}

To investigate whether the long-term level of functioning can be predicted at an early stage, the raw scores on the DRS long-term were correlated with the initial Glasgow Coma Scale scores (iGCS), the length of stay at the ICU (as indicators of injury severity), the age at injury, and the levels of consciousness at EINP admission and discharge as determined by means of the PALOC-s. Table 3 shows that only the last two variables correlated significantly with the long-term scores on the DRS (PALOC-s at admission $r=-0.51$ and PALOC-s at discharge $r=-0.79$, respectively).
Table 3

Spearman correlation coefficients between predictor variables and DRS long-term raw scores in TBI patients only $(N=32)$

\begin{tabular}{lcc}
\hline & Correlation & $p$-value \\
\hline Initial GCS & -0.21 & 0.25 \\
Length of stay at ICU & 0.28 & 0.17 \\
Age & -0.21 & 0.25 \\
PALOC-s admission & -0.51 & $<0.01$ \\
PALOC-s discharge & -0.79 & $<0.01$ \\
\hline
\end{tabular}

\section{Discussion}

The aim of this study was twofold. The first objective was to investigate the course of recovery of all patients and the long-term level of dependency of the TBI patients among a group of children and young adults who remained unconscious for at least one month and at most six months after severe brain injury and who underwent an intensive neurorehabilitation program. The second was to identify factors that could predict recovery.

\subsection{Course of recovery}

At admission, three-quarters of the patients were in a vegetative state. At discharge, two-thirds of the patients were conscious and could be admitted to a regular rehabilitation program. Boyer and Edwards [26], describing a similar treatment program for children and adolescents with TBI, found that of 83 patients who were in VS after 3 months and $43 \%$ were still in VS after one year. In the present study of 24 TBI patients who were in VS at admission, a comparable proportion of patients (33\%) remained in VS.

In a preliminary report, Melchers et al. [27] presented some results of a controlled, prospective, and randomised study to investigate the effects of a twostage multimodal program applied to children and adolescents with TBI. Starting with stimulation while the patient was in a coma at the ICU, this was followed by cognitive-neuropsychological rehabilitation as soon as the patients regained consciousness. Although no direct effects of the stimulation program were found, the overall long-term outcome of the experimental group was more favourable than that of the control group.

Recently, Liscio et al. [28] compared the outcome of a cognitive-behavioural stimulation protocol for severely brain-damaged children in the postacute stage with a previously provided regular rehabilitation program. They found a significant improvement in the level of consciousness in the experimental group compared to the control group. They con- 
cluded that the findings seemed to support their hypothesis that multisensory stimulation combined with cognitive-behavioural therapy would increase the rate of spontaneous recovery. No follow-up data were collected in this study.

Recovery in nTBI patients was generally less favourable, in agreement with the chances of recovery calculated by the Multi-Society Task Force [3] and a more recent case-controlled study [29]. In this study, onethird of all nTBI patients regained full consciousness, while one-third remained in VS and one-third were in MCS at discharge.

In the long-term ( 2 to 5 years after injury), the majority (57\%) of the TBI patients (16 of the 28 surviving patients) were able to function partially or completely independently. This percentage is somewhat higher than the percentages found in the study by Boyer and Edwards, where $27-43 \%$ achieved independence in activities of daily living [26]. Lammi reported that $50 \%$ of adults who were in MCS one month after TBI functioned independently 2 to 5 years post injury [30]. Giacino and Kalmar reported the same percentage of MCS patients at 12 months post injury, while only $3 \%$ of the VS patients attained this level of independence [31], It is also important to note that $60 \%$ of all the patients who remained in VS died within a few years. The remaining patients showed some recovery to a state of extremely severe disability.

\subsection{Prediction of recovery}

In regards to the first research question, i.e. which factors can predict recovery, the following conclusions can be drawn.

Firstly, the level of consciousness at admission was found to be highly predictive of recovery of consciousness. In the present study, all patients in MCS (P5 or P6 on the PALOC-s) or in a VS highly active state (P4) recovered to consciousness. This finding is in agreement with a recent study by Dolce et al. [32], who found that the appearance of spontaneous motility and eye tracking (both aspects assessed in the PALOC-s) was significantly correlated with positive outcome.

Half of the patients who initially scored P2 (VS hypo-reactive) or P3 (VS reflexive) on the PALOC-s recovered to consciousness, while the other half did not. Almost all patients who ultimately recovered to a higher level of consciousness showed some recovery within 6 weeks after admission to EINP.

Age, gender, initial Glasgow Coma Scale score, or length of stay at the ICU were not correlated to de- gree of recovery. This means that when a patient ultimately proceeds from coma to VS, these types of information cannot be used to predict further recovery. Multilevel regression analyses only showed a relation between time since discharge from the ICU and the level of consciousness, reflecting a gradual improvement, rather than a sudden change in the level of consciousness. It is not clear whether this reflects spontaneous recovery [33] or is triggered by the treatment given.

The long-term level of functioning of the patients in this study was significantly correlated with the level of consciousness observed at admission, as well as at discharge from EINP. No other variable correlated with the long-term DRS scores. This result underlines the importance of the PALOC-s as a clinical tool in predicting the long-term level of disability [20].

\subsection{General}

Compared to the authors' earlier retrospective study [19], the outcome of this prospective study was somewhat less favorable, with $62 \%$ fully conscious at discharge in the retrospective study versus $54 \%$ in this study. The main cause of this difference was presumably the higher proportion of patients in a VS at admission (43\% versus $75 \%$ ), since the initial level of consciousness proved to be highly associated with the level of consciousness at discharge. The general outcome results in the present study seem somewhat better than those found in historical data [2,3], and comparable to the figures found after similar programs, when age, the severity of the injuries, and the duration of the unconscious state ate taken into account. However, it is difficult to compare the studies due to possible differences in treatments and methodology.

The question whether EINP contributed to this finding cannot be answered, however. We strongly recommend further investigations into the effects of such neurorehabilitation programs.

\subsection{Limitations}

An important limitation of the present study is the size of the group of patients studied (44) in relation to the variety of causes of injury and to the age range, which resulted in a heterogeneous study sample. We acknowledge the large developmental range of the participants and the possible confounding effect of age versus etiology, but the sample size unfortunately does not allow separate analyses for age groups. 
Although the number of patients in this study was rather small, each patient was observed at several time points so that the total number of observations for the statistical analyses was 390. This number of observations ensures the reliability of the analyses.

One might question whether all discriminating variables were incorporated in this study. They were likely not, as variables such as premorbid functioning, type and size of injuries, initial treatments provided at the ICU, or the influence of close relatives on recovery [34] were not included due to lack of reliable information. There is a chance, therefore, that the prediction of recovery can be improved by incorporating one or more of these variables.

We compared the rates of recovery before and after starting EINP, using PALOC-s scores determined by the repeated measurements. This process was hampered by the fact that few pre-treatment measurements were available for most of the patients. Future outcome research should include at least three measurements for all patients at time points before treatment starts.

The DRS scores were collected by telephone interview. Although this kind of data collection has been found to be reliable [35-37], this has recently been questioned [38]. We therefore cannot rule out that the long-term level of functioning may be less (or more) favorable than was reported by the respondents.

The conclusions of this study are only valid for severely injured young patients. We investigated a program meant for severely injured patients, and the study included no moderately or mildly injured patients and no patients over 25 years of age.

Only one patient received neurostimulants, which reflects the timeframe in which the study was performed. In the last 10 years the use of neurostimulants in unconscious patients has grown (39) without clear evidence of the effects. On the one hand, neurostimulants can confound the results, which is not the case in this study; on the other hand, not using neurostimulants limits comparisons with more recent outcome studies in which patients probably did get neurostimulants.

Finally, no long-term outcome was measured in the nTBI group, nor were follow-up data available. Since the study was executed some time ago, it would have been of interest to execute a follow-up study. Now, the level of functioning eventually reached by the participants remains unknown.

\section{Conclusions}

This is the first study to systematically investigate the course of recovery in a cohort of children and young adults in prolonged VS or MCS after severe brain injury. Although the study sample was relatively small and heterogeneous, the results are nevertheless important for insights into the course and prediction of recovery. We identified three patterns of recovery in an early phase after admission to EINP, which enabled prediction, in an early stage and with high level of probability, of whether recovery of consciousness would occur. These results can play an important role in clinical decision-making and are of great importance for further research. It would be especially valuable to repeat this study in patients over the age of 25 years. Furthermore, possibilities to evaluate the effects of the EINP treatment by using sufficient pre-treatment examinations should be investigated.

\section{Acknowledgements}

This study was part of a larger evaluation project of the rehabilitation program "Early Intensive Neurorehabilitation Programme (EINP) for children and young adults in a vegetative or minimally conscious state after severe brain injury". The study was approved by the medical ethical committee METOPP. We are grateful to all members (H. van Daal, P.L. Hoenderdaal, J.C.M. Lavrijsen, A.I.R. Maas, A.J.H.Prevo, H. Stroink, A.J.J.M. Vingerhoets and H. van der Vlugt) of the scientific advisory committee of the research project for their contribution to the design of this study, and their advice on the execution and processing of the data. We are very grateful to the students who assisted by examining the patients.

The study was funded by: Stichting Centraal Fonds RVVZ, Johanna Kinderfonds, Stichting Bio Kinderrevalidatie, CZ groep Zorgverzekeringen, Zorgverzekeraar VGZ, Zorg en zekerheid, and Hersenstichting Nederland. Further financial support provided by Gerritsen Beheer groep was essential for starting and continuation of the overall project.

\section{Conflict of interest}

The authors report no conflicts of interest. The authors alone are responsible for the content and wording of the paper. 


\section{References}

[1] B. Jennett, Part I: Definitions, diagnosis, prevalence and ethics, Neuropsychol Rehabil 15(3-4) (2005), 163-165.

[2] Multi-Society Task force on persistent vegetative state, medical aspects of the persistent vegetative state (first of two parts), New Engl J Med 330(21) (1994), 1499-1508.

[3] Multi-Society Task Force on Persistent Vegetative State, Medical aspects of the persistent vegetative state, (second of two parts) New Engl J Med 330(22) (1994), 1572-1579.

[4] J.T. Giacino and K. Kalmar, Diagnostic and prognostic guidelines for the vegetative and minimally conscious states, Neuropsychol Rehabil 15(3-4) (2005), 166-174.

[5] K. Andrews, International working party on the management of the vegetative state, Brain Inj 10(11) (1996), 797-806.

[6] J.T. Giacino, N.D. Zasler, D.I. Katz, J.P. Kelly, J.H. Rosenberg and C.M. Filley, Development of practice guidelines for assessment and management of the vegetative and minimally conscious states, J Head Trauma Rehab 12(4) (1997), 79-89.

[7] J.T. Giacino, S. Ashwal, N. Childs, R. Cranford, B. Jennett, D.I. Katz et al., The minimally conscious state, definition and diagnostic criteria, Neurology 58(2002), 349-353.

[8] M.R. Coleman, The assessment and rehabilitation of vegetative and minimally conscious patients, Neuropsychol Rehabil 15(3-4) (2005), 161-162.

[9] S. Ashwal, Pediatric vegetative state: Epidemiological and clinical issues, Neurorehabilitation 19(4) (2004), 349-360.

[10] L. Elliott and L. Walker, Rehabilitation interventions for vegetative and minimally conscious patients, Neuropsychol Rehabil 15(3-4) (2005), 480-493.

[11] B. Jennett, Vegetative survival: The medical facts and ethical dilemmas, Neuropsychol Rehabil 3(2) (1993), 99-108.

[12] A. Shiel, J.P.S. Burn, D. Henry, J. Clark, B.A. Wilson, M.E. Burnett et al., The effects of increased rehabilitation therapy after brain injury: Results of a prospective controlled trial, Clin Rehabil 15(2001), 501-514.

[13] K. Andrews, Rehabilitation practice following profound brain damage, Neuropsychol Rehabil 15(3-4) (2005), 461-472.

[14] F.C. Wilson, J. Harpur and N. McConnell, Vegetative and minimally conscious state(s) survey: Attitudes of clinical neuropsychologists and speech and language therapists, Disabil Rehabil 29(22) (2007), 1751-1756.

[15] A. Shiel and B.A. Wilson, Can behaviours observed in the early stages of recovery after traumatic brain injury predict poor outcome? Neuropsychol Rehabil 15(3-4) (2005), 494 502 .

[16] J. Whyte, D. Katz, D. Long, M.C. Dipasquale, M. Polansky, K. Kalmar et al., Predictors of outcome in prolonged posttraumatic disorders of consciousness and assessment of medication effects: A multicenter study, Arch Phys Med Rehab 86(3) (2005), 453-462.

[17] G. Teasdale and B. Jennett, Assessment of coma and impaired consciousness, A practical scale, Lancet 2 (1974), 81-84.

[18] J.P. Marcin, A.D. Slonim, M.M. Pollack and U.E. Ruttimann, Long-stay patients in the pediatric intensive care unit, Crit Care Med 29(3) (2001), 652-657

[19] H.J. Eilander, V.J.M. Wijnen, J.G.M. Scheirs, P.L.M. de Kort and A.J.H. Prevo, Children and young adults in a prolonged unconscious state due to severe brain injury: Outcome after an early intensive neurorehabilitation programme, Brain Inj 19(6) (2005), 425-436.

[20] H.J. Eilander, M. van de Wiel, M. Wijers, C.M. van Heugten, D. Buljevac, J.C.M. Lavrijsen et al., The reliability and validity of the PALOC-s: A post-acute level of consciousness scale for assessment of young patients with prolonged disturbed consciousness after brain injury, Neuropsychol Rehab 19(1) (2009), 1-27.

[21] B.J. Ansell, J.E. Keenan and O. de la Rocha, Western neuro sensory stimulation profile, a tool for assessing slow-torecover head-injured patients, Handbook, Tustin, California: Western Neuro Care Centre, 1989.

[22] M. Rappaport, K.M. Hall, K. Hopkins, T. Belleza and D.N. Cope, Disability rating scale for severe head trauma: Coma to community, Arch Phys Med Rehab 63 (1982), 118-123.

[23] H.J. Eilander, R.B.W. Timmerman, J.G.M. Scheirs, C.M.V. Heugten, P.L.M.D. Kort and A.J.H. Prevo, Children and young adults in a prolonged unconscious state after severe brain injury: Long-term functional outcome as measured by the DRS and the GOSE after early intensive neurorehabilitation, Brain Inj 21(1) (2007), 53-61.

[24] R.M. Bullock, R.E. Merchant, S.C. Choi, C.B. Gilman, J.S. Kreutzer, A. Marmarou et al., Outcome measures for clinical trials in neurotrauma, Neurosurg Focus 13(1) (2002), 1-11.

[25] W.D. Gouvier, P.D. Blanton, K.K. LaPorte and C. Nepomuceno, Reliability and validity of the disability rating scale and the levels of cognitive functioning scale in monitoring recovery from severe head injury, Arch Phys Med Rehab 68 (1987), 94-97.

[26] M.G. Boyer and P. Edwards, Outcome 1 to 3 years after severe traumatic brain injury in children and adolescents, Injury 22(4) (1991), 15-20.

27] P. Melchers, A. Maluck, L. Suhr, S. Scholten and G. Lehmkuhl, An early onset rehabilitation program for children and adolescents after traumatic brain injury (TBI): Methods and first results, Restor Neurol Neuros 14(2-3) (1999), 153160.

[28] M. Liscio, A. Adduci, S. Galbiati, G. Poggi, D. Sacchi, S. Strazzer et al., Cognitive-behavioural stimulation protocol for severely brain-damaged patients in the post-acute stage in developmental age, Disabil Rehabil 30(4) (2008), 275-285.

[29] N.K. Cullen, Y.G. Park and M.T. Bayley, Functional recovery following traumatic vs non-traumatic brain injury: A casecontrolled study, Brain Inj 22(13-14) (2008), 1013-1020.

[30] M.H. Lammi, V.H. Smith, R.L. Tate and C.M. Taylor, The minimally conscious state and recovery potential: A followup study 2 to 5 years after traumatic brain injury, Arch Phys Med Rehab 86(4) (2005) 746-754.

[31] J.T. Giacino and K. Kalmar, The vegetative and minimally conscious states: A comparison of clinical features and functional outcome, J Head Trauma Rehab 12(4) (1997), 36-51.

[32] G. Dolce, M. Quintieri, S. Serra, V. Lagani and L. Pignolo, Clinical signs and early prognosis in vegetative state: A decisional tree, data-mining study, Brain Inj 22(7) (2008), 617623.

[33] G. Kwakkel, B. Kollen and J. Twisk, Impact of time on improvement of outcome after stroke, Stroke 37(9) (2006), 2348-2353.

[34] J. Whyte, Clinical trials in rehabilitation: What are the obstacles? Am J Phys Med Rehab 82(10) (2003), S16-21.

[35] N. Korner-Bitensky, S. Wood-Dauphinée, J. Siemiatycki, S. Shapiro and R. Becker, Health-related information postdischarge: Telephone versus face-to-face interviewing, Arch Phys Med Rehab 75 (1994), 1287-1296.

[36] C.P. Cusick, C.A. Brooks and G.G. Whiteneck, The use of proxies in community integration research, Arch Phys Med Rehab 82 (2001), 1018-1024.

[37] L.E. Pettigrew, J.T. Wilson and G.M. Teasdale, Reliability of ratings on the glasgow outcome scales from in-person and 
telephone structured interviews, J Head Trauma Rehab 18(3) (2003), 252-258.

[38] S.A. LeGrand, B.J. Hindman, F. Dexter, L.G. Moss and M.M Todd, Reliability of a telephone-based glasgow outcome scale assessment using a structured interview in a heterogenous population of patients and examiners, J Neurotraum 24(9) (2007), 1437-1446.

\section{Appendix 1 \\ Short Description of the Early Intensive Neurorehabilitation Programme (EINP)}

The Early Intensive Neurorehabilitation Programme (EINP) was developed for the treatment of children and young adults up to 25 years of age, who are in a vegetative or minimally conscious state. It starts as soon as possible after they leave the intensive care unit, within six months after traumatic injury or within three months in case of a non-traumatic cause. The program has to be administered for three months, or for a shorter time if consciousness has been recovered. The basic philosophy of the program is that an active approach may induce recovery of brain functions in many severely injured patients, but only when all important health threats have been identified and treated, and when known principles of the development and growth of brain tissue are taken into account. The treatment program focuses on several domains:

- Improving the metabolic state, the state of nourishment, respiration and skin condition, as well as reducing the risk of infections. The actual treatment activities depend on the individual situation of each patient. Special attention is given to the removal of invasive devices, like a tracheostomy tube or a bladder catheter.

- Recovering the normal circadian cycles by offering a homelike environment, which is structured and filled with daily activities.
- Improving arousal and awareness by structured stimulation of all sensory modalities (vision, hearing, smell, taste, touch, posture and motion, pain and temperature) in such a way that maximal arousal will be generated. As soon as the patient shows any voluntary reactions, reflecting a change from VS into MCS, the program focuses on stimulating and training cognitive functions, the contents depending on age and cognitive status.

- Improving normal posture and motor activities by intensive physiotherapy, occupational therapy and oro-facial therapy, using sitting aids, a variety of splints and other appliances.

- Improving the ability of the family to cope with the situation and their own feelings, by giving support, education including psycho-education, training them to handle the patient and, when necessary, providing treatment.

Each day, five half-our treatment activities (sensory stimulation, physiotherapy, occupational therapy, oral therapy or activity therapy) are scheduled in such a way that these activities alternate with necessary resting periods, with moments of personal care and with family visits. The program is carried out by a specialized team, consisting of a rehabilitation physician, a neuropsychologist, a stimulation therapist, physiotherapists, occupational therapists, speech therapists, nursing staff, a social worker and activity therapists. The team works according to a written protocol, describing all procedural steps in the program from admission to discharge, and outlining the content of the program at the different stages of recovery. Patients' condition and progress are evaluated by the whole team on the basis of a weekly schedule, which may result in changes being made to the content and the intensity of parts of the program. When necessary, changes can be made on a daily basis. 